\title{
PARASITAS GASTROINTESTINAIS EM OVINOS CRIADOS NA REGIÃO DO PLANALTO NORTE CATARINENSE
}

\author{
Juliano Biolchi* \\ Daniela Pedrassani*
}

\begin{abstract}
RESUM0: A exploração na ovinocultura vem contribuindo ao longo dos anos no agronegócio brasileiro e para a economia mundial, concentrando seus rebanhos principalmente nas regiões Nordeste e Sul. Entretanto, mesmo com a crescente demanda de produtos como a carne, leite e lã, ainda se apresentam limitações pelas inúmeras condições de manejo sanitário. Devido as parasitoses gastrointestinais diretamente interferirem na sanidade dos rebanhos, objetivou-se avaliar a ocorrência de parasitas gastrointestinais em rebanhos ovinos dos municípios de Canoinhas e Três Barras, Estado de Santa Catarina. Entre maio e junho de 2019, foram examinadas, pela técnica de Gordon e Whitlock e coprocultura, amostras fecais de 103 ovinos puros e mestiços e de diferentes faixas etárias procedentes de quatro rebanhos. As variáveis (raça, idade, gênero e rebanho) foram analisadas pelos testes de Student e qui-quadrado. Observou-se em $67,96 \%$ dos ovinos amostrados a presença de oocistos do gênero Eimeria e $80,58 \%$ de positivos para ovos de helmintos gastrointestinais, dos quais a ordem Strongylida e os gêneros Trichuris sp., Toxocara sp. e Moniezia sp. estavam presentes. Dentre estes, 64,08\% estavam com infecção mista por helmintos e protozoários. As larvas identificadas das coproculturas indicaram infecções pelos gêneros: Haemonchus, Oesophagostomum, Trichostrongylus Cooperia e Ostertagia. 0 grau de infecção parasitária apresentou diferença estatística para os helmintos da ordem Strongylida quando comparados os borregos com animais adultos $(\mathrm{p}=0,011)$. Os gêneros Haemonchus e Trichostrongylus mostraram ser os mais importantes e abundantes no parasitismo gastrointestinal detectado nos ovinos do Planalto Norte Catarinense.
\end{abstract}

PALAVRAS-CHAVE: Ovinocultura; OPG; Coprocultura; Parasitismo.

\section{GASTROINTESTINAL PARASITES IN SHEEP BRED IN THE NORTHERN PLATEAU OF SANTA CATARINA, BRAZIL}

\begin{abstract}
For many years sheep breeding has greatly benefitted Brazilian agribusiness and world economy, with herds mainly concentrated in the northeastern and southern regions of the country. However, although there has been a growing demand in meat, milk and wool, limitations due to numberless conditions in sanitary management are present. Gastrointestinal parasitosis interferes directly in the herds' health. Current analysis evaluates the occurrence of gastrointestinal parasites in sheep herds in Canoinhas and Três Barras SC Brazil. Fecal samples of 103 pure and crossbreed sheep and different age brackets from four herds were examined between May and June 2019 by Gordon and Whitlock technique and coproculture. Variables (race, age, genus and herd) were analyzed by Student and chi square tests, demonstrating $67.96 \%$ of sampled sheep with oocytes of genus Eimeria and $80.58 \%$ positive for gastrointestinal helminth eggs, featuring the order Strongylida and genera Trichuris sp., Toxocara sp. and Moniezia sp. Further, $64.08 \%$ had mixed infection by helminths and protozoa. Larvae identified by coproculture showed infection by genera Haemonchus, Oesophagostomum, Trichostrongylus Cooperia and Ostertagia. Degree of parasite infection provided statistical difference for Strongylida helminths when lambs and adult animals were compared $(p=0.011)$. Genera Haemonchus and Trichostrongylus proved to be the most important and abundant in gastrointestinal parasitism in sheep in the northern plateau of the state of Santa Catarina, Brazil.
\end{abstract}

KEYWORDS: Sheep breeding; OPG; Coproculture; Parasitism.

\footnotetext{
Graduando no curso de Medicina Veterinária, Universidade do Contestado (UNC). Bolsista PIBIC/CNPq, Santa Catarina, Brasil.

** Médica veterinária. Doutora em Medicina Veterinária pela UNESP. Docente do curso de Medicina Veterinária da Universidade do Contestado (UnC) e do Programa de Mestrado em Desenvolvimento Regional (UnC), Santa Catarina, Brasil. E-mail: daniela@unc.br
} 


\section{INTRODUÇÃo}

No Brasil, a exploração de ovinos cresce gradativamente e tem como objetivos a produção sustentável de carne, do leite e de lã. 0 rebanho nacional é de aproximadamente 18,9 milhões de cabeças, estando concentrado principalmente nas regiões Nordeste e Sul (IBGE, 2018). Apesar do incremento de novas tecnologias e aspectos relacionados ao manejo, as parasitoses gastrointestinais subclínicas ainda representam o maior e mais grave problema sanitário dos rebanhos, por vezes, inviabilizando economicamente a criação, em decorrência do impacto negativo nos índices produtivos em criações extensivas (SCHILD et al., 2015; COSTA et al., 2011).

Nos ovinos, os nematódeos apresentam distribuição binomial negativa no rebanho, e os animais podem albergar simultaneamente inúmeras espécies. 0 parasitismo pode ser influenciado pela raça dos ovinos, frequência de tratamentos anti-helmínticos, manejo e condições ambientais (LOPES et al., 2013). Destacamse entre os encontrados na região Sul do Brasil: Haemonchus contortus, Trichostrongylus colubriformis, Ostertagia ostertagi, Cooperia curticei, Strongyloides sp., Nematodirus spatigher, Oesophagostomum venulosum e Trichuris ovis (DOMINGUES et al., 2013).

0 Haemonchus contortus parasita 0 abomaso e é a espécie hematófaga mais patogênica sendo responsável por quadros severos de anemia nos animais (VIEIRA et al., 2018; GILLEARD, 2013). Já o Trichostrongylus sp. ocasiona enterite, atrofia das vilosidades e consequentemente diminuição da digestão e absorção de nutrientes e, o gênero Oesophagostomum, que apesar de pouco frequente, possui patogenicidade aguda pelas larvas histotróficas em intestino delgado e grosso, causarem formação de nódulos, fibrose ou abscessos na parede intestinal, além de provocar quadros diarreicos graves nos animais (AMARANTE, 2005).

Protozoários coccídios do gênero Eimeria são frequentemente encontrados nas fezes de ovinos, independe da idade, apesar de animais jovens serem os mais susceptíveis e eliminarem maior quantidade de oocistos (REEG et al., 2005). Ainda que o sistema de produção seja um fator que influi diretamente sobre as características da eimeriose, apenas as altamente patogênicas podem manifestar quadro clínico severo caracterizado por diarreia escura, profusa, desidratação, anorexia, letargia, alta mortalidade, redução na conversão alimentar e baixa qualidade de lã dos que se recuperam da infecção (BRINKER, 2014; LIMA, 2004).

Métodos alternativos de controle como 0 manejo das pastagens, pastoreio misto ou alternado entre diferentes espécies de herbívoros, seleção genética de animais resistentes às infecções por nematódeos visando minimizar os problemas causados pelas parasitoses, bem como a adoção de exames complementares para monitorar o grau de infecção e, a partir do resultado, buscar estratégias para reduzir a carga parasitária bem como a resistência do uso de drogas anti-helmínticas quando necessária, estão entre as alternativas utilizadas (OLIVEIRA et al., 2017; MACIEL et al., 2014; DUARTE et al., 2012).

Por serem animais de valor zootécnico e econômico, contribuem no agronegócio brasileiro e para a economia mundial. Tendo em vista que as parasitoses gastrointestinais têm ampla distribuição geográfica associada à alta prevalência na espécie ovina, é necessária elevada atenção quanto à sanidade dos rebanhos. Por conseguinte, o presente estudo teve como objetivo avaliar a ocorrência de parasitas gastrointestinais em rebanhos ovinos dos municípios de Canoinhas e Três Barras, Estado de Santa Catarina.

\section{METODOLOGIA}

\section{1 ÁREA DE ESTUDO}

0 estudo foi conduzido com rebanhos ovinos de um centro de educação profissional e de propriedades particulares nos municípios de Canoinhas $\left(26^{\circ} 1040 S\right.$ Lat. e $50^{\circ} 23250$ Lon.) e Três Barras ( $26^{\circ} 657 S$ Lat. e $50^{\circ} 18290$ Lon.), no Planalto Norte Catarinense. 0 clima na região é temperado (Cfb) com verão de temperaturas brandas e chuvas igualmente distribuídas durante 0 ano, bem como geadas durante a estação do inverno (TOMPOROSKI; MARCHESAN 2016). A temperatura média anual é de $17^{\circ} \mathrm{C}$ e a precipitação pluviométrica média é de 1.450 mm (CLIMATE-DATA.ORG, 2019). 


\subsection{POPULAÇÃO E AMOSTRAGEM}

Foram coletadas, no período de maio e junho de 2019, amostras fecais de 103 ovinos procedentes de quatro diferentes rebanhos. 0 período do estudo foi correspondente à época seca nos municípios. Os animais amostrados eram criados em sistema extensivo, permanecendo durante 0 dia em pastagens cultivadas e a noite em apriscos suspensos com piso ripado. A idade dos ovinos variou de sete meses a oito anos, e 31,07\% eram de raças puras (Ile-de-France, Santa Inês e Texel) e 68,93\% mestiços, com cruzas das mesmas raças (Tabela 1).

Tabela 1. Categorias etárias dos ovinos amostrados nos municípios de Canoinhas e Três Barras, no Planalto Norte Catarinense

\begin{tabular}{cccc}
\hline \multirow{2}{*}{ Categoria } & \multicolumn{2}{c}{ Origem } & Total \\
\cline { 2 - 3 } & Puro & Mestiço & \multirow{2}{*}{$N^{\circ}(\%)$} \\
\cline { 2 - 3 } & $\mathrm{N}^{\circ}(\%)$ & $\mathrm{N}^{\circ}(\%)$ & \\
\hline FJ & $21(60,0)$ & $14(40,0)$ & \multirow{2}{*}{$91(88,35)$} \\
\hline FA & $07(12,5)$ & $49(87,5)$ & \\
\hline MJ & $01(20,0)$ & $04(80,0)$ & \multirow{2}{*}{$12(11,65)$} \\
\hline MA & $03(42,86)$ & $04(57,14)$ & \\
\hline
\end{tabular}

Nota: FJ: Fêmea jovem; FA: Fêmea adulta; MJ: Macho jovem; MA: Macho adulto

\subsection{COLETA E PROCESSAMENTO DAS AMOSTRAS FECAIS}

Promoveram-se colheitas em animais vermifugados em um período maior de 30 dias. As amostras fecais foram coletadas diretamente da ampola retal, com auxílio de sacos plásticos e, posteriormente, acondicionadas em caixa isotérmica e identificadas individualmente. Estas foram analisadas pela técnica de Gordon e Whitlock, modificadas (1939), sensível para 100 ovos de helmintos gastrointestinais (OPG) e 100 oocistos de coccídeos (0oPG) por grama de fezes. As coproculturas foram realizadas por propriedade a partir de pool de fezes dos animais (ROBERTS; O'SULLIVAN, 1950). Posteriormente, as larvas de terceiro estágio $\left(\mathrm{L}_{3}\right)$ recuperadas das coproculturas foram identificadas com base na descrição de Ueno e Gonçalves (1998).

\subsection{ANÁLISE ESTATÍSTICA}

Os valores de $\mathrm{OPG} / 0 \mathrm{oPG}$ foram transformados em $\left(\log _{10}[0 P G+1]\right)$ e, posteriormente, analisados estatisticamente. As médias de OPG/00PG entre as diferentes categorias etárias e entre os sexos foram comparadas pelo teste de Student $(\mathrm{T})$ e as categoria foram ainda comparadas pelo teste de qui-quadrado

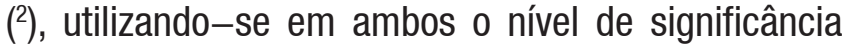
$5 \%$, considerando resultados significativos quando $(p \leq 0,05)$.

\section{RESULTADOS}

Das 103 amostras fecais examinadas, 70 $(67,96 \%)$ apresentavam 0ocistos do gênero Eimeria e $83(80,58 \%)$ mostraram-se positivas para ovos de helmintos gastrointestinais (Tabela 2) das quais além da ordem Strongylida $(79,61 \%)$, foram ainda observados ovos de parasitas dos gêneros Trichuris, Toxocara e Moniezia $(0,97 \%, 2,91 \%$ e 7,76\%, respectivamente (Figura 1).

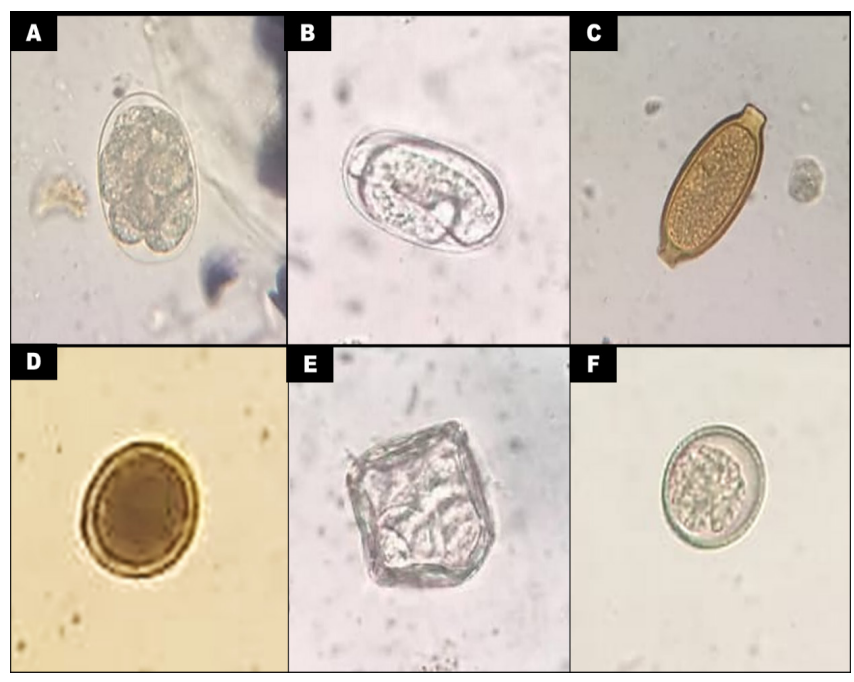

Figura 1. Ovos de parasitas (400x) observados nas amostras fecais de ovinos naturalmente infectados e procedentes dos municípios de Canoinhas e Três Barras/SC. Legenda: A - Ovo da ordem Strongylida (1000x); B - Ovo de Strongyloides sp. (1000x); C - Ovo de Trichuris sp. (1000x); D - Ovo de Toxocara sp. (400x); E - Ovo de Moniezia sp. (400x) e F - Oocisto de Eimeria sp. (1000x). Fonte: BIOLCHI, 2019. 
Tabela 2. Distribuição das variáveis parasitismo por helmintos $(n=83)$, parasitismo por Eimeria $(n=70)$ e infecção parasitária $(n=93)$ dos ovinos naturalmente infectados dos municípios de Canoinhas e Três Barras/SC

\begin{tabular}{lccc}
\hline \multirow{3}{*}{ Categoria } & Macho N (\%) & Borrego N (\%) & Puro N (\%) \\
\cline { 2 - 4 } & Fêmea N (\%) & Adulto N (\%) & Mestiço N (\%) \\
& [Valor de P] & [Valor de P] & $30(93,7)$ \\
\hline \multirow{3}{*}{ Parasitsimo por Helmintos } & $9(75)$ & $33(97,1)$ & $53(74,6)$ \\
& $74(81,3)$ & $50(72,5)$ & {$[0,023]^{*}$} \\
\hline \multirow{3}{*}{ Parasitsimo por Eimeria } & {$[0,603]$} & {$[0,003]^{*}$} & $25(78,1)$ \\
& $7(58,3)$ & $27(79,4)$ & $45(63,4)$ \\
& $63(69,2)$ & $43(62,3)$ & {$[0,137]$} \\
\hline \multirow{2}{*}{ Infecção Parasitária } & {$[0,447]$} & {$[0,080$} & $31(96,9)$ \\
& $10(83,3)$ & $33(97,0)$ & $62(87,3)$ \\
& $83(91,2)$ & $60(86,9)$ & {$[0,129]$} \\
\hline
\end{tabular}

Nota: * indica diferença estatística significativa $(p \leq 0,05)$ pelo teste de qui-quadrado.

Dentre os positivos, $64,08 \%$ estavam com infecção mista por helmintos e protozoários. A carga parasitária foi considerada baixa para Strongyloides (OPG médio de 42,72, variando de 0 a 500) e alta para os parasitas da ordem Strongylida (OPG médio de 1641,75 , variando de 0 a 23.400) e para Eimeria (0oPG médio de 883,50, variando de 0 a 21.500). Apesar das altas cargas parasitárias, a maioria do rebanho total amostrado não apresentava sinais clínicos de helmintose ou coccidiose; apenas $8,73 \%$ dos animais estavam apáticos, com diarreia e/ou edema submandibular.

0 parasitismo foi mais prevalente em borregos $(P=0,003)$ e nos ovinos puros $(p=0,023)$ (Tabela 2$)$. Em relação ao grau de infecção parasitária (OPG/0oPG), as médias de OPG da ordem Strongylida dos borregos foram estatisticamente superiores às observadas nos adultos $(p=0,011)$ (Tabela 3$)$. Pelo pequeno número de animais positivos, os demais parasitas detectados não puderam ser avaliados estatisticamente.

Tabela 3. Contagens de ovos de helmintos gastrointestinais e oocistos de eimerídeos por grama de fezes de ovinos naturalmente infectados e procedentes dos municípios de Canoinhas e Três Barras/SC

\begin{tabular}{lccc}
\hline \multirow{2}{*}{ Categoria } & Macho N (\%) & Borrego N (\%) & Puro N (\%) \\
\cline { 2 - 4 } & Fêmea N (\%) & Adulto N (\%) & Mestiço N (\%) \\
& {$[$ Valor de P] } & {$[$ Valor de P] } & $1451,22 \pm 3438,81^{\mathrm{a}}$ \\
\hline \multirow{2}{*}{ Borregos } & $2292,68 \pm 4272,28^{\mathrm{a}}$ & $63,41 \pm 122,49^{\mathrm{a}}$ & $(23,69 \%)$ \\
\hline \multirow{2}{*}{ Adultos } & $(18,63 \%)$ & $(19,31 \%)$ & $508,06 \pm 803,48^{\mathrm{a}}$ \\
& $1211,29 \pm 1972,15^{\mathrm{b}}$ & $29,03 \pm 70,45^{\mathrm{a}}$ & $(15,81 \%)$ \\
\hline \multirow{2}{*}{ Puros } & $(16,28 \%)$ & $(24,26 \%)$ & $793,75 \pm 1026,50^{\mathrm{a}}$ \\
& $1187,50 \pm 1035,54^{\mathrm{a}}$ & $62,50 \pm 126,86^{\mathrm{a}}$ & $(12,93 \%)$ \\
\hline \multirow{2}{*}{ Mestiços } & $(8,72 \%)$ & $(20,29 \%)$ & $923,94 \pm 2687,29^{\mathrm{a}}$ \\
& $1846,48 \pm 3704,69^{\mathrm{a}}$ & $33,80 \pm 76,81^{\mathrm{a}}$ & $(29,08 \%)$ \\
\hline
\end{tabular}

Nota: Letras iguais na coluna indicam diferença estatística não significativa $(\mathrm{p}>0,05)$ pelo teste de T. 
A infecção por parasitas da ordem Strongylida e por coccídios do gênero Eimeria foi superior nos ovinos da propriedade A (91,3\% e $82,6 \%$, respectivamente). A prevalência de Strongyloides foi baixa em todas as propriedades e a localidade $\mathrm{C}$ foi a que obteve 0 maior percentual de ovinos parasitados (32\%). A maior média de OPG para os nematódeos da ordem Strongylida foi na propriedade C, seguido pela média de Strongyloides na propriedade A e de Eimeria na B (Gráfico 1), demonstrando que 0 grau de infecção foi mais alto mesmo nos rebanhos com menos animais infectados.

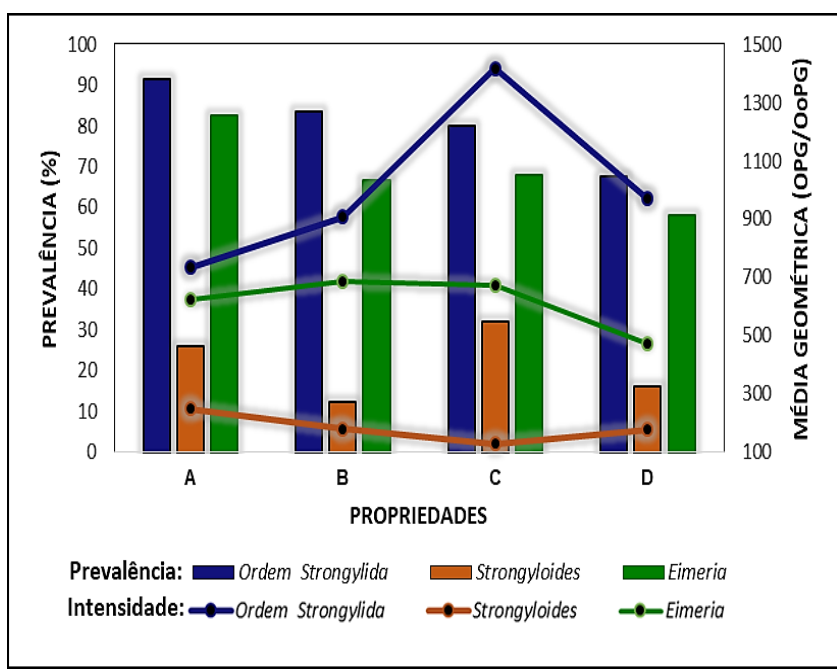

Gráfico 1. Prevalência de infecção por parasitas e média geométrica $(\mathrm{OPG} / \mathrm{OO} \mathrm{PG})$ em ovinos amostrados por propriedades $(n=103)$.

As larvas recuperadas das coproculturas indicaram infecções mistas pelos seguintes gêneros: Haemonchus, Ostertagia e Trichostrongylus identificados em todas as propriedades amostradas e Oesophagostomum e Cooperia identificados em 3 e 2 das quatro propriedades avaliadas, respectivamente (Gráfico 2).

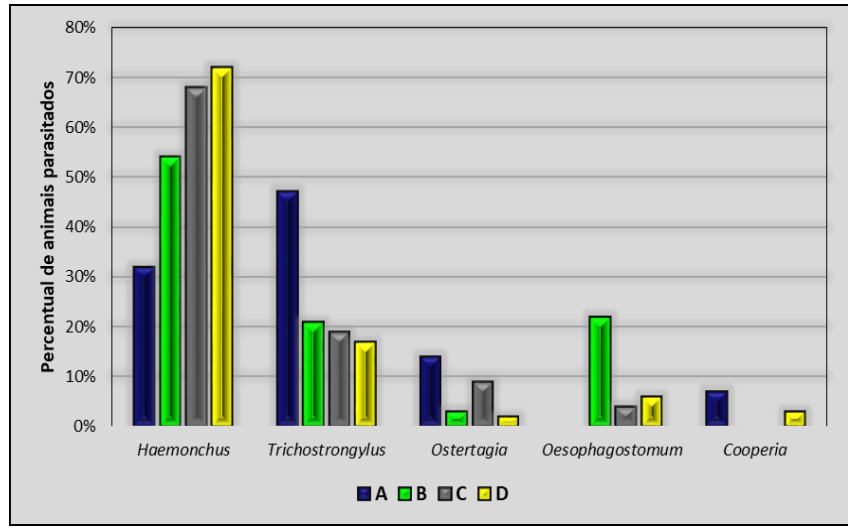

Gráfico 2. Percentual de gêneros de helmintos identificados por coprocultura $\left(\mathrm{L}_{3}\right)$, em ovinos naturalmente infectados e criados em propriedades de Canoinhas e Três Barras, Santa Catarina.

\section{DISCUSSÃo}

No que diz respeito à ocorrência de parasitoses gastrointestinais, a média de OPG/0oPG foi elevada nos rebanhos ovinos amostrados, em todas as categorias. Esses índices altos podem ser justificados pela permanência diária, em torno de 14 horas, dos animais em aprisco comunitário, o qual favorece as infecções, pela aglomeração dos animais e à baixa frequência de limpeza, algumas vezes com fezes quase em contato direto com os animais, favorecendo a sobrevivência $e$ 0 desenvolvimento das larvas infectantes, contribuindo positivamente para a infecção e reinfecção dos animais. A qualidade do pasto nas criações extensivas também favorece 0 parasitismo (AHID et al., 2008). A baixa qualidade do pasto nos períodos de outono $\mathrm{e}$ inverno é outro fator que propicia o parasitismo clínico, embora seja desfavorável a sobrevivência das fases pré-parasitárias (AMARANTE, 2004).

Mesmo em época de acentuado frio e período seco para os municípios amostrados (ambiente desfavorável para as formas pré-parasitárias), foi observada alta eliminação de oocistos de Eimeriae ovos de helmintos pelos ovinos amostrados nas distintas propriedades. Provavelmente a baixa qualidade das pastagens e 0 fato de diversas fêmeas estarem em período gestacional devem ter interferido na resposta imune favorecendo o parasitismo.

A imunidade inata está presente desde 0 
nascimento, não é específica e pode responder aos diferentes agentes da mesma forma sem produzir células de memória. Entretanto, a defesa imune adquirida por meio da ingestão do colostro atua por um maior período que a inata a apresenta especificidade e memória, desta forma garantindo ao longo de seu desenvolvimento uma proteção mais efetiva, por sua capacidade de memorizar e reconhecer expressivo número de antígenos (SCHAFER et al., 2015). Pelo alto parasitismo, animais jovens devem ficar nas melhores pastagens e/ou receber suplementação de melhor qualidade em relação aos demais animais do rebanho, haja vista que a verminose uma vez presente pode agravar e ocasionar debilidade do sistema imunológico, deixando-0s ainda mais vulneráveis às demais infecções parasitárias (CORRÊA et al., 2018).

A maior prevalência do gênero Haemonchus spp. é similar ao relatado por outros autores para a espécie ovina. Domingues et al. (2013); Ferraz et al. (2019) e Vieira et al. (2018) afirmam ser a espécie mais patogênica e relativamente comum de helmintos em áreas tropicais e subtropicais onde no verão ocorrem temperaturas amenas e altos índices de chuva. Apesar de baixa a porcentagem dos animais com sinais clínicos sugestivos para hemoncose, deve-se dar importância também aos animais resilientes, que aumentam a contaminação ambiental com ovos do parasita e servem de fontes de infecção para os ovinos suscetíveis (RETORE; CORREA, 2015).

No Brasil algumas raças mestiças de ovinos como a Santa Inês já demonstraram ser mais resistentes a infecções parasitárias em comparação a raças oriundas de outros continentes como ovelhas Suffolk, Ile de France, Poll Dorset, Dorper e Texel (AMARANTE, 2004; BUENO et al., 2002). Portanto, a alta prevalência de infecção por helmintos nos animais puros, quando comparados aos mestiços, pode estar relacionada às raças mestiças por disporem de características selecionadas pela resistência genética contra nematódeos gastrointestinais passadas de geração para geração, pela herdabilidade que, para resistência ao parasitismo, varia de 0,3 a 0,5. (AMARANTE, 2004).
A hemoncose em ovinos já foi estudada no planalto catarinense por Ramos et al. (2004), os quais evidenciaram por meio de necropsias a presença de nematódeos das espécies $H$. contortuse T. colubriformis, corroborando com a alta prevalência e intensidade de larvas destes gêneros diagnosticados nos ovinos amostrados em Canoinhas e Três Barras. Ainda, os autores relataram que, mesmo depois de décadas e de diversos estudos realizados na espécie ovina pelo Brasil, em comparação à fauna helmintológica dos dias de hoje não houve alterações significativas. 0 gênero Haemonchus ainda é o mais prevalente nos rebanhos ovinos, apesar de que possíveis variações no manejo, emprego de drogas anti-helmínticas ou até mesmo alterações climáticas globais durante o referido período tenham ocorrido.

Segundo em ordem de importância para as condições brasileiras, a tricostrongilose está presente em praticamente todas as criações de ovinos (CARDIA et al., 2011). Maciel et al. (2014) detectaram a prevalência de 90,9\% para 0 gênero Trichostrongylus, similar ao encontrado no presente estudo. 0 fato de serem parasitas com elevada capacidade de resistir à dessecação e prevalecerem em áreas onde ocorrem chuvas uniformes e temperaturas baixas, deve ter contribuído para alta detecção de larvas desse gênero, pois a área estudada apresenta essas características climáticas.

Oocistos de Eimeria são frequentes em ovinos de todas as faixas etárias, entretanto a manifestação da coccidiose tem maiores consequências em borregos com menos de três meses de idade, uma vez que animais adultos dificilmente apresentam complicações e estes constituem-se a principal via de infecção aos animais jovens (LIMA, 2004).

Hassum e Menezes (2005) detectaram 94,65\% de prevalência de 0ocistos de Eimeria em ovinos criados em sistema intensivo, no oeste do Rio Grande do Norte. A alta positividade tem relação direta com o sistema intensivo de criação, pois em animais mantidos em confinamento é comum que haja a ingestão de alimentos e água contaminada com material fecal contendo oocistos. No presente 
estudo alta porcentagem (67,96\%) de positivos também foi diagnosticada e os animais são criados extensivamente, mas podem ter contato com as fezes com oocistos no período que ficam no aprisco.

Desta forma, torna-se indispensável a identificação correta das espécies de parasitos presentes no rebanho ovino, uma vez que se almeja um diagnóstico mais apropriado para assegurar que um programa mais oportuno para o combate de helmintos e protozoários seja adotado pelos produtores (VIEIRA et al., 2018; STARLING et al., 2017; MACIEL, 2014).

Diante da alta frequência parasitária gastrointestinal de alguns ovinos amostrados, notase a importância de avaliações parasitológicas frequentes e da associação de técnicas de manejo empregadas para diminuir a frequência de aplicação dos vermífugos, bem como identificar os animais mais sensíveis que são minoria e, na medida do possível, eliminá-los do rebanho, visto que podem abrigar metade dos parasitas existentes no grupo. Essas estratégias podem contribuir para a melhoria da qualidade sanitária e produtiva dos rebanhos ovinos.

\section{CONCLUSÃO}

0 parasitismo gastrointestinal foi alto; estava presente em todos os rebanhos amostrados, principalmente nos animais jovens. Os gêneros de helmintos gastrointestinais mais importantes $\mathrm{e}$ abundantes detectados em ovinos criados em sistema extensivo na região do Planalto Norte Catarinense foram Haemonchus e Trichostrongylus.

\section{AGRADECIMENTOS}

Aos alunos da graduação em medicina veterinária da Universidade do Contestado, pelo auxílio nas coletas. Ao centro de educação profissional Vidal Ramos e aos proprietários das fazendas, pela disponibilização dos animais para execução deste estudo.

\section{REFERÊNCIAS}

AHID, S. M. M.; SUASSUNA, A. C. D. et al. Parasitas gastrintestinais de caprinos e ovinos da região oeste do Rio Grande do Norte, Brasil. Ciência Animal Brasileira, Goiás, v. 9, n. 1, p. 212-218, jan./mar. 2008.

AMARANTE, A. F. T. Controle de verminose ovina. Revista do Conselho Federal de Medicina Veterinária, Brasília, v. 11, n. 34, p. 19-30, jan./abr. 2004.

BRINKER, J. C.; ROCHA, A. G. et al. Identificação de espécies de Eimeria spp. em ovinos participantes na $33^{a}$ exposição internacional de animais no município de Esteio, RS. Revista Agrocientífica, Santa Catarina, v. 1, n. 1, p. 61-68, jan./jun. 2014.

BUENO, M. S.; CUNHA, E. A. et al. Infección por nematodos em razas de ovejas carniças criadas intensivamente em la región del sudeste del brasil.

Archivos de Zootecnia, argentina, v. 51, p. 273-280, 2002.

CARDIA, D. F. F.; ROCHA-OLIVEIRA, R. A. et al. Immune response and performance of growing Santa Ines lambs to artificial Trichostrongylus colubriformis infections. Veterinary Parasitology. v. 182, n. 2-4, p. 248-258, 2011.

CLIMATE-DATA.ORG. Disponível em: https:// pt.climate-data.org/america-do-sul/brasil/santacatarina/canoinhas-43657/. Acesso em: 10 jul. 2019.

CORRÊA, M. R.; MARTINS, A. A. et al. Identificação de nematódeos pastrintestinais em ovinos no município de Dom Pedrito, RS. In: ANAIS DO SALÃO INTERNACIONAL DE ENSINO, PESQUISA E EXTENSÃO, 2017, p. 1-5. Anais [...]. 2017.

COSTA, V. M. M.; SIMÕES, S. V. D.; CORREA, F. R. Controle das parasitoses gastrintestinais em ovinos e 
caprinos na região semiárida do Nordeste de Brasil. Pesquisa Veterinária Brasileira, v. 31, n. 1, p. 6571, 2011.

DOMINGUES, L. F.; GIGLIOTI, R. et al. In vitro and in vivo evaluation of the activity of pineapple (Ananas comosus) on Haemonchus contortus in Santa Inês sheep. Veterinary Parasitology, v. 197, p. 263-270, 2013.

DUARTE, E. R.; SILVA, R. B. et al. Diagnóstico do controle e perfil de sensibilidade de nematódeos de ovinos ao albendazol e ao levamisol no norte de Minas Gerais. Pesquisa Veterinária Brasileira, v. 32, n. 2, p. 147-152, 2012.

FERRAZ, A.; CASTRO, T. A. et al. Levantamento de Parasitos Gastrintestinais Diagnosticados em Ovinos p elo Laboratório de Doenças Parasitárias da Universidade Federal de Pelotas (Brasil), nos Anos de 2015 a 2017. Revista Brasileira de Zoociências, v. 20, n. 1, p. 1-7, maio 2019.

GILLEARD, J. S. Haemonchus contortus as a paradigm and model to study anthelmintic drug resistance.

Parasitology Research, v. 140, n. 12, p. 1506-1522, 2013.

GORDON, H. M. L.; WHITLOCK, H. V. A new technique for counting nematode eggs in sheep faeces.

Journal of the Council for Scientific and Industrial Australian, v.12, n.1, p.50-52, 1939.

HASSUM, I. C.; MENEZES, R. C. A. A. Infecção natural por espécies do gênero Eimeria em pequenos ruminantes criados em dois municípios do estado do Rio de Janeiro. Revista Brasileira de Parasitologia Veterinária, v. 14, n. 3, p. 95-100, 2005.

IBGE. Instituto Brasileiro de Geografia e Estatística. Sistema IBGE de Recuperação Automática - SIDRA. 2018.
LIMA, J. D. Coccidiose dos ruminantes domésticos. Revista Brasileira de Parasitologia Veterinária, v. 23, n. 1, p. 9-13, set. 2004.

LOPES, J.; SANCHES, J. M. et al. Avaliação de diferentes princípios ativos no controle de helmintos gastrintestinais em rebanho ovino na região do Taiano - Roraima. Revista Brasileira de Ensino de Ciências Agrárias, v. 1, p. 85-103, jan./jun. 2013.

MACIEL, W. G.; FELIPPELLI, G. et al. Helminth fauna of sheep from the micro region of Jaboticabal, São Paulo State, Brazil. Ciência Rural, . v. 44, n. 3, p. 492- 497, jan./jun. 2014.

RAMOS, C. I.; BELLATO, V. et al. Epidemiologia das helmintoses gastrintestinais de ovinos no Planalto Catarinense. Ciência Rural, . v. 34, n. 6, p. 18891895, 2004.

REEG, K. J.; GAULY, M. et al. Coccidial infections in housed lambs: 0ocyst excretion, antibody levels and genetic influences on the infection. Veterinary Parasitology, v. 127, p. 209-219, 2005.

RETORE, M.; CORREA, E. B. Principais Doenças Diagnosticadas nos Rebanhos Ovinos de Mato Grosso do Sul. Embrapa Agropecuária Oeste, Dourados, MS: 2015.

ROBERTS, F. H. S.; O'SULLIVAN, J. P. Methods for egg counts and larval cultures for strongyles infesting the gastrointestinal tract of cattle. Australian Journal of Agricultural Research, , v. 1, p. 99-102, 1950.

SCHAFER, A. S.; LEAL, M. L. R. et al. Immune response of lambs experimentally infected with $\mathrm{Hae}-$ monchus contortus and parenterally treated with a combination of zinc and copper. Small Ruminant Research. v. 123, n. 1, p. 183-188, 2015.

SCHILD, A. L. et al. Doenças diagnosticadas pelo Laboratório Regional de Diagnóstico no ano 2014. 
Boletim do Laboratório Regional de Diagnóstico, v. 37, n. 1, p. 9-27, 2015.

STARLING, R. Z. C.; MARTINS, I. V. et al. Diagnóstico in vivo da sensibilidade de nematoides a diferentes antihelmínticos em ovinos criados em sistema semiintensivo. Archives of Veterinary Science, v. 22, n. 2, p. 38-47, jun. 2017.

TOMPOROSKY, A. A.; MARCHESAN, J. Planalto norte catarinense: algumas considerações sobre aspectos históricos, características físico-naturais e extrativismo. Estudos sobre alternativas de desenvolvimento territorial para o Planalto Norte Catarinense (PNC), v. 6, n. 2, 2016.

UENO, H.; GONÇALVES, P. C. Manual para diagnóstico das helmintoses de ruminantes. 2. ed. Japan International Cooperation Agency (JICA), p. 143, 1988.

VIEIRA, V. D.; RIET-CORREA, W. et al. Controle de parasitas gastrintestinais em ovinos e análise financeira de uma fazenda com sistema de pastejo rotacionado irrigado no semiárido nordestino.

Pesquisa Veterinária Brasileira, v. 38, n. 5, p. 913919, maio 2018.

Recebido em: 21/08/2019

Aceiro em: 27/09/2019 